\title{
Natural heritage and urban growth: ethics, sustainability education and governance
}

\author{
J. Lutas Craveiro ${ }^{1} \&$ I. Duarte de Almeida ${ }^{2}$ \\ ${ }^{I}$ Buildings Department, National Laboratory of Civil Engineering, \\ Portugal \\ ${ }^{2}$ Higher Institute of Educative Sciences, Portugal
}

\begin{abstract}
The relationship between urban and rural areas can no longer be considered a territorial antagonism. Urban growth and the density of both buildings and population pushes the rural world into a position dependent on political action, commonly expressed in terms of lacking technology and scarce resources. Additionally, for the first time in human history, the bulk of the population occupies urban areas. Nevertheless, since the 'non-urban' type has the privilege of a better environmental, the emergence of environmental issues has changed the social value of both rural and non-urbanized areas. The 'rural world' now seems to be the holder of the traditions as well as the local identity values.

In the present paper the main question can be sketched out in the following terms: how has the urban growth shifted the opposite urban-rural relationship into city-hinterland integration? This question is one step ahead of the dichotomy 'modernity-tradition' and leads us to think in terms of 'change-conservation' dichotomy. We must regard a city as a macro-organism that achieves and maintains its balance through an equitable distribution of functions: residence, public/private services, and leisure.

To rule a city is to develop policies that promote well-being and citizen involvement. A city without participation is not sustainable and a city threatened by the scarcity of resources or by environmental risks becomes a frightened city. Public participation cannot be a result of collective fear. We must think about urban planning as territorial planning of land uses. There is a democratic form of doing that: public participation and environmental concern as a civil value.

We discuss in this work some questions on environmental ethics, the contents of public campaigns of sustainability education and we present a reflection about urban areas subjected to quick growth in Portugal.

Keywords: urban sustainability, sustainability education, global change.
\end{abstract}




\section{Introduction}

The relationship of dependency between human communities and the respective environmental conditions has changed over time. For more than 6,000 years those communities evolved and become centers of commerce, communication, technological developments, education, religion, social change, political power, and progress. They have also been centers of crowding, pollution, and disease.

In the last three centuries, since the beginning of the Industrial Revolution, when major changes in agriculture, manufacturing, and transportation had a profound effect on the socioeconomic and cultural conditions in Europe, cities have been growing rapidly in size. Nowadays, we talk about urban areas (towns or cities and their contiguous suburban fringes with populations of more than 2,500 people), degree of urbanization (percentage of its population living in urban areas) and urban growth (rate of increase of urban populations).

\section{The urban civilization and the emergence of environment}

The course of human civilization is illustrated by an appropriation in large scale of natural resources through increasingly sophisticated technology. We were the hunters or the farmers of the past, but now we become urban residents. This evolution of human occupation is accompanied by a growing rupture between the city and nature, since the relations of dependency humankind-environment become mediated by infrastructures, and public policies.

The rural, with the urban population increasing, loses the characteristics maintained for several centuries, focusing on the main function of food production to urban communities. The medieval cities are still marked by this dependence city-hinterland.

The rural areas reproduced, traditionally, a dynamic social anchored in family structures and relations of land ownership, as advocates João Ferrão [1].

Between 1950 and 2010, the number of people living in the world's urban areas increases 4 fold, from approximately 736 million up to 3,164 million (Table 1).

At the beginning of the twenty-first century, and in a global point of view, we can emphasize an unprecedented historic turning point in which the urban population exceeds the barrier of $50 \%$ of the world population (Figure 1). By 2050 it is projected to reach 6,398 million people, almost equal to the world's current population. About $90 \%$ of this urban growth will occur in developing countries.

In the countries with High Human Development index, urban population reaches more expressive values. However, the processes of urbanization are also significant in other regions of the world [2].

Portugal, a semi-developed country on the periphery of Europe, as argued by Boaventura de Sousa-Santos [3], is currently experiencing some strong urban mutations that lead to the strengthening of its metropolitan areas; simultaneously, the country presents a drastic decline of agricultural activities around the major cities. The suburbanization of surrounding areas in large cities has been 
accentuated in the last decade mainly in the big cities always located in coastal zone. It is also in the coastal areas that we find the municipalities with up to $40 \%$ of its territory assigned to urban occupation.

Table 1: $\quad$ World urban population (thousands) 1950-2010 [13].

\begin{tabular}{|c|c|}
\hline Year & Urban Population \\
\hline 1950 & 736796 \\
\hline 1955 & 854955 \\
\hline 1960 & 996298 \\
\hline 1965 & 1160982 \\
\hline 1970 & 1331783 \\
\hline 1975 & 1518520 \\
\hline 1980 & 1740551 \\
\hline 1985 & 1988195 \\
\hline 1990 & 2274554 \\
\hline 1995 & 2557386 \\
\hline 2000 & 2853909 \\
\hline 2005 & 3164635 \\
\hline 2010 & 3494607 \\
\hline 2015 & 3844664 \\
\hline
\end{tabular}

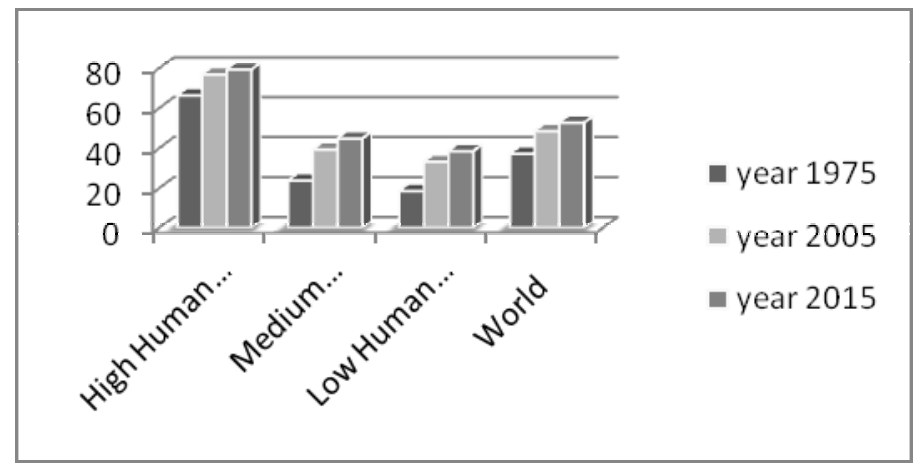

Figure 1: Demographic trends (urban population of $\%$ of total).

The large cities also illustrate the highest urban growth in the last decade (Figure 2) accordingly to research of Teresa Pinto Correia [4], which brings relevant concerns about the territorial cohesion.

Moreover, the urban sprawl identified in Portuguese cities affects permanently the surrounding rural areas, which means that the city expands very quickly occupying their periphery. This is often due to the construction of infrastructure and equipment that support the own urban sprawl. As is argued by Teresa Salgueiro, the territorial plans, even when designated plans for 'improvement', are always plans for urban expansion [5]. 


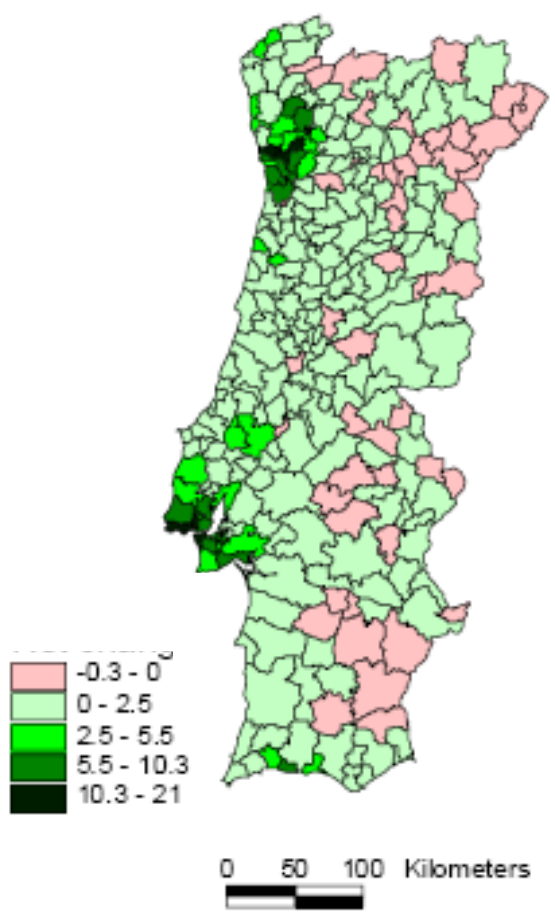

Figure 2: $\quad$ Urban sprawl in Portugal (1990-2000).

Like in other countries, Portuguese urban populations grow in two ways: by natural increase (more births than deaths) and by immigration (mostly from rural areas). Because cities are the main centers for new jobs, higher income, education, innovation, culture better health care, and trade, people are pulled to urban areas in search of jobs, a better life, and freedom from the constraints of village cultural life. They may also be pushed from rural areas into urban areas by factors such as poverty, lack of land or declining agricultural work.

Currently in Portugal, 6 persons out of every 10 lives in a city and some analysts expect this number to increase to at least 8 by 2030 (Figure 3).

One problem of our urban growth is the loss of rural land, fertile soil, and wildlife habitats as cities get bigger. As urban areas expand they swallow up land, especially flat or gently rolling land with well-drained, fertile soil.

Once prime agricultural land or forestland is paved over or built upon, it is lost for food production and habitat for most of its former wildlife. As a city expands, more energy is needed to transport food to its people; this in turn causes more pollution. In coastal areas and riversides, urban growth destroys or pollutes ecologically valuable wetlands. 


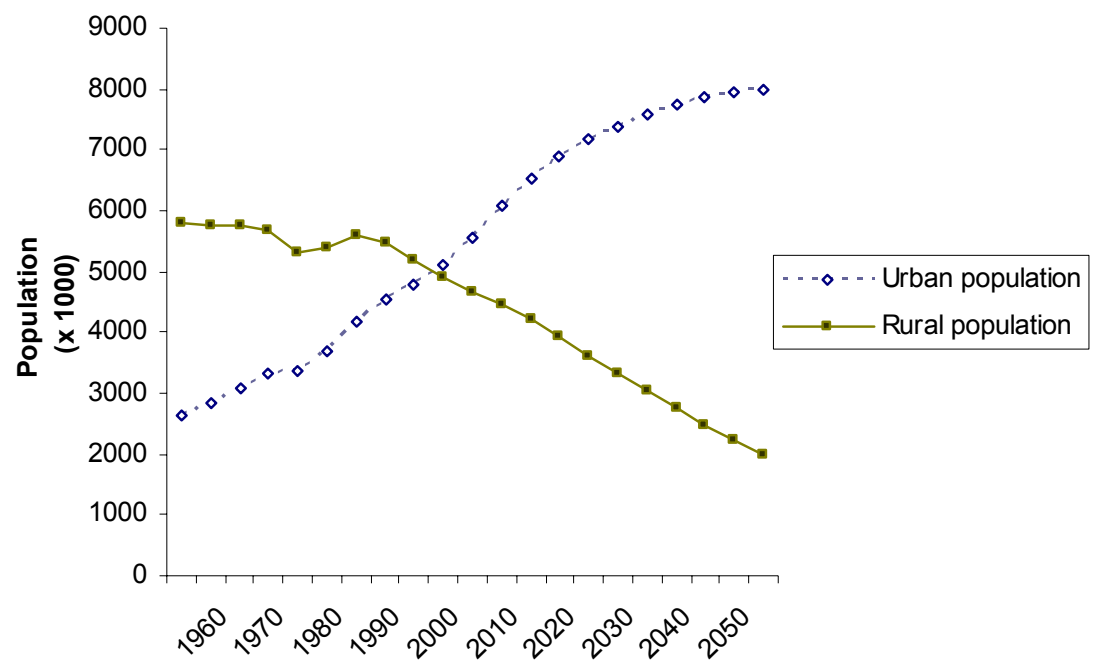

Figure 3: A century of changes. Demographic trends (Portuguese urban and rural population growth, from the early 1950 s to 2050) [13].

The municipalities at the south metropolitan area of Lisbon are now exposed to strong urban pressure considering the decisions of location of new transport infrastructure (new bridge and new Lisbon airport). Since 2001 Alcochete, for example, has a population increase of about $50 \%$, and the government has took measures in order to contain urban sprawl. There is also a concomitant decline of rural areas.

As land values near urban areas rise, many farmers prefer to sell their land. They can make much more money selling to developers than raising potatoes or cattle.

The urban expansion could give rise to the spread of urban ideology and building to rural areas, often described as modernization, but which could also be called social urbanization. The rural spaces assume urban characteristics like the development of secondary (industry) and especially tertiary (services) activities and the appearance of new services and businesses.

In this perspective of structural changes we should reconsider the urban occupation as a linear process of metabolism that broke the bonds of complementarities between the city and the agricultural hinterland. The sustainable city requires the rehabilitation of the surrounding rural areas (Figure 4).

It is necessary to promote a different logic of urban development that differs from a mere addition of urban areas, as the Schumacher Society strongly stresses, as is illustrates by the last Figure adapted from Herbert Giraldet [6]. 


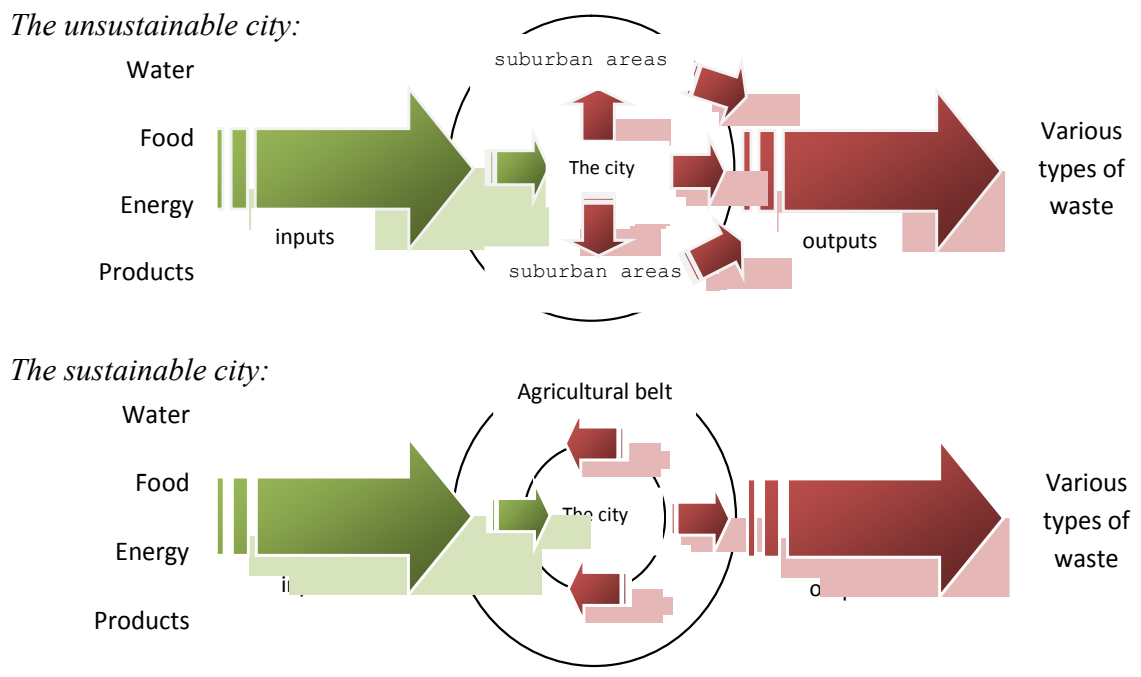

Figure 4: $\quad$ Patterns of relationship city-hinterland.

We must exploit a socio-ecological perspective. It's urgent to discuss models of human habitat. Some issues of environmental ethics must be reflected too as scientific process to produce privileged knowledge.

Although urban problems must be solved in existing cities, building new cities and towns could take some of the pressure off overpopulated and economically depressed urban areas. However, new towns rarely succeed without government financial support. Some don't succeed even then, primarily because of poor planning and management

An important goal in incoming decades should be to make urban areas more self-reliant, sustainable, and enjoyable places to live. In an sustainable and ecologically city, called an ecocity or green city, people walk or cycle for most short trips; they walk or bike to bus or metro stops for longer urban trips. In such cities, emphasis is placed on pollution prevention, recycling and reuse (at least $60 \%$ of all municipal wastes), use of renewable energy resources, encouraging rather than assaulting biodiversity, and use composting to help create rather than destroy soil.

Because most people around the world now live, or will live, in urban areas, improving the quality of urban life is an urgent priority. Increased urbanization and urban density are better than spreading people out over the countryside, which would destroy more of the planet's resources and biodiversity. The primary problem is not urbanization, but our failure to make most cities more sustainable and livable and to provide economic support to rural areas.

Urban areas that fail to become more ecologically sustainable over the next few decades are inviting economic depression and increased unemployment, pollution, and social tension. 


\section{Facing social and ecological global crisis}

Humanity is facing a global ecological and social crisis. Climate change imposes a relationship of uncertainty about the future of humankind. The question of our narrative, as human species, is no longer the anticipation of a great future, but the possibility that there is no future to come.

Traditional narratives about human history (capitalism and communism) did fail. We can now only manage scarcity and restore the utopia through the ecology. However, environmental risks and scarcity reinforces the responsibility of science, argues Craveiro [7]. Science is subject to a strong assessment of their social consequences.

For example, regarding urban planning we know that the major conurbations are located in coastal areas (it's the case of Portugal). Climate change can endanger coastal areas. The risk of erosion becomes so a risk to human occupation. But solutions can't be just view by a technical perspective.

Similarly, the solutions for the global ecological and social crisis must be found among science, political power and civil society. However, environmental risks put into question the technocratic paradigm of modern societies, because the risk calls for public debate as states Eduarda Gonçalves [8].

Thus, the issue of urban sustainability has to meet the subjectivity of citizens and their demands for quality of life. The environment is no longer conceived as a set of non-urban qualities.

But the quality of life has a price. Environmental policies can sacrifice expectations of progress. Even the conception of landscape and natural heritage may object to the forms of urban expansion. The concept of landscape may object to the concept of land use as alert Phil Macnaghten and John Urry [9].

So, urban sustainability claims for an ethical perspective and for public participation based on information and Sustainability education.

The city should not be planned as a blind mechanism that can only react to external conditions.

Urban construction and agriculture were always the main forces of change of the natural environment as is argued by Ana Subtil, Carla Dias, Sílvia Esteves, Susana Marques and Isabel Duarte de Almeida [10]. The relationship between city and hinterland has to rehabilitate the rural areas as resources for subsistence and environmental sustainability.

The future of humanity is played in the models of urban development.

\section{Sustainable cities and sustainable education}

The concept of sustainable development will be barely achieved if we look only for science knowledge or economic progress. It is indispensable include human development, values, and differences in cultures. The concept transcends the classical development paradigm, and consists of the following two components:

1) Sustainable Human Development, and

2) Environmental Sustainability 
Sustainable Human Development (SHD) represents an evolution of the classical concept of development: its emphasis has moved from the material well being of states to the well being of individual human beings.

While the classical approach was based on three factors of production, namely land, capital and labor (human beings), the new paradigm of SHD places people at the centre, as the principal actor and the ultimate goal of development.

By enhancing human capabilities to expand choices and opportunities for men, women and children, SHD creates an environment in which human security is guaranteed and individual human beings can develop their full potential and lead a life of dignity and freedom.

Sustainable human development is opposed to sustainable development because it emphasizes issues such as the importance of gender equality, participation in decision-making processes, and access to education and health [11].

\section{Final considerations and conclusions}

Cities are major consumers and distributors of goods and services. Many of them tend to drain resources out of external regions that they depend on. As a result of increasing consumption of resources, and growing dependencies on trade, the ecological impact of cities extends beyond their geographic locations. It has been recognized that the concept of sustainable development is an evolving, debatable term. The term sustainability is a difficult concept to define as it refers more to a process rather than an end-point. The most widely known definition of sustainable development comes from the Brundtland Commission, which defined sustainable development as "development that meets the needs of the present without compromising the ability of future generations to meet their own needs"12].

A sustainable city can generally be defined as "one that has put in place action plans and policies that aim to ensure adequate resource availability and (re-)utilization, social comfort and equity and economic development and prosperity for future generations". Effective governance at different scales such as regional bodies, national agencies, or local authorities can achieve the path towards sustainability. For example, Agenda 21 prescribes lifestyle changes. Agenda 21 is a comprehensive plan of action to be taken globally, nationally and locally by organizations of the United Nations System, Governments, and Major Groups in every area in which human impacts on the environment.

Sustainability education develops skills, knowledge and values that promote behavior in support of a sustainable environment.

\section{References}

[1] Relações entre o Mundo Rural e o Mundo Urbano, Sociologia, Problemas e Práticas, n. 33, pp. 45-54, 2000

[2] Human Development Report 2007/2008, Fighting Climate Change: Human Solidarity in a Divided World, United Nations Development Programme, 2008 . 
[3] Pela Mão de Alice: o Social e o Político na Pós-modernidade. Ed. Afrontamento, 1994.

[4] Estudo sobre o Abandono em Portugal Continental: Análise das Dinâmicas de Ocupação do Solo, do Sector Agrícola e da Comunidade Rural, Tipologia das Áreas Rurais, Ed. Universidade de Évora, 2006.

[5] A Cidade em Portugal, Uma Geografia Humana, Edições Afrontamento, Porto, 1992.

[6] Criar Cidades Sustentáveis, Edições Sempre-em-pé, Colecção Cadernos Shumacher, Águas Santas, 2007.

[7] O Homem e o Habitat: Território, Poderes Públicos e Conflitos Ambientais, Ed. Laboratório Nacional de Engenharia Civil, 2007.

[8] Os Portugueses e os Novos Riscos. Imprensa de Ciências Sociais, Série Estudos e Investigações, Lisboa, pp. 11-19, 2007.

[9] Contested Natures. Sage Publications, London, 1999.

[10] Ecologia Social, A Água e o Ambiente, Espaço, n. 9, pp. 79-102, 2005.

[11] Global Issues and The United Nations. ONU Global Seminar, Kanazawa Session 20 November 2001, Lec5 Online. http://www.unu.edu/hq/ japanese/gs-j/ gs2001j/ kanazawa1/ Lec5-text-e.pdf

[12] Rees, William E. and Roseland, Mark. Sustainable Communities: Planning for the 21st Century. Plan Canada. 31: pp. 3-15, Canada, 1991.

[13] Population Division of the Department of Economic and Social Affairs of the United Nations Secretariat, World Population Prospects: The 2006 Revision and World Urbanization Prospects: The 2007 Revision, http://esa.un.org/unup, Sunday, May 18, 2008; 9:14:24 PM. 